\title{
A novel treatment strategy of new onset atrial fibrillation after cardiac surgery: an observational prospective study
}

Mohamed Zeriouh ${ }^{1 \dagger}$, Anton Sabashnikov $^{1 * \dagger}$, Yeong-Hoon Choi ${ }^{1,3+}$, Javid Fatullayev ${ }^{1}$, Hannes Reuter ${ }^{2}$, Aron-Frederik Popov ${ }^{4}$, Georg Langebartels ${ }^{1}$, Lucas Kimmig ${ }^{2}$, Parwis B Rahmanian', Thorsten Wittwer ${ }^{1,3}$, Klaus Neef ${ }^{3}$, Jens Wippermann ${ }^{1}$ and Thorsten Wahlers ${ }^{1,3}$

\begin{abstract}
Objective: The aim of this prospective observational study was to evaluate the efficiency of a new escalating treatment strategy with vernakalant, flecainide and electrical cardioversion (EC) in patients with new onset atrial fibrillation (AF) after cardiac surgery.
\end{abstract}

Material and methods: 24 patients with new onset AF after aortic valve surgery, coronary artery bypass surgery or combined procedures were evaluated in this study. Additional including criteria were age between 18 and 80, duration of AF less than four days, body weight less than $100 \mathrm{~kg}$ and no previous treatment with class I or III antiarrhythmic drugs. Exclusion criteria were poor left ventricular ejection fraction (LVEF $<40 \%$ ) and history of myocardial infarction within 30 days. The patients were divided into converters and non-converters according to their response to combination treatment with vernakalant and flecainide, and the groups were compared.

Results: The mean age of the population was $69.6 \pm 6.3$ years and $26.1 \%$ of patients were female. There were no statistically significant differences between the two groups in terms of height, weight, gender distribution, comorbidities, preoperative medication, left ventricular function and left atrium diameter. Interventricular septum (IVS) in the non-converted group was significantly thicker compared to the converted group: $14.0 \pm 1.00 \mathrm{vs.} 10.40 \pm 2.59 \mathrm{~mm}$ $(p=0.036)$. While 14 patients (60.9\%) were successfully converted into stable sinus rhythm by pharmacological treatment with vernakalant and flecainide, 9 patients (39.1\%, non-converted group) remained in AF. However, seven of them could be converted after additional EC.

Conclusion: The combination of vernakalant and flecainide improves the conversion rate into a stable sinus rhythm in postcardiotomy patients with new onset AF compared to single drug therapy. Furthermore it might be an excellent precondition for successful EC in patients who are not converted after using both antiarrhtythmic drugs. Furthermore, left ventricular hypertrophy might be a potential negative predictor of successful pharmacological cardioversion.

Keywords: Vernakalant, Flecainide, Recent onset atrial fibrillation post cardiac surgery, Electrical cardioversion, Antiarrhythmic drugs

\footnotetext{
* Correspondence: anton.sabashnikov@uk-koeln.de

${ }^{\dagger}$ Equal contributors

'Department of Cardiothoracic Surgery, Heart Center of the University of

Cologne, Cologne, Germany

Full list of author information is available at the end of the article
} 


\section{Background}

Postoperative atrial fibrillation (AF) is the most common complication after cardiac surgery, which occurs in up to $74 \%$ of patients who underwent on-pump and off-pump procedures [1,2]. Furthermore, it may contribute to longer hospital stays which can be associated with deterioration in heart failure, prolonged inotropic support, use of intraaortic balloon pump, and increased risk for cerebrovascular accidents [3,4]. After more than a century of research, the etiology and pathophysiology of this arrhythmia is still not completely understood $[2,5]$. In terms of treatment, there are several drugs, such as digitalis, Beta-blockers, calcium channel-blockers, and pharmacological or electrical cardioversion (EC), which were shown as efficient treatment strategies of AF in patients undergoing cardiac surgery [6]. The choice of treatment in each individual case depends on a number of factors, such as age, comorbidities and clinical status of patients with AF. Also, duration and etiology of AF play a major role in the treatment choice [7].

If not approached within a short period of time, a delayed cardioversion may aggravate AF-associated symptoms and promote structural changes of the atria [8]. Therefore, it is of particular interest to achieve early cardioversion in patients with AF, especially when they suffer from distressing symptoms or seriously compromised cardiac function [1,3,9-11].

Vernakalant is an antiarrhythmic agent, which is used for rapid cardioversion of recent onset atrial fibrillation. It blocks early-activating $\mathrm{K}^{+}$atrial channels and frequencydependent atrial $\mathrm{Na}^{+}$channels, prolongs atrial refractory periods and decreases atrial conduction without promoting ventricular arrhythmia [12]. Flecainide is a class Ic antiarrhythmic agent, which can be used for the prevention of ventricular and supraventricular arrhythmias [13]. Electrical cardioversion delivers a direct current synchronization with the $\mathrm{R}$ wave. It is usually done using external, transcutaneous electrode patches or internal cardiac electrodes [14]. All these treatment strategies have been shown as valuable options in case of postcardiotomy AF [12-14], however so far there has been no evidence regarding efficacy of stepwise escalating therapy using vernacalant, flecainide and EC after cardiac surgery.

In this study, we created a new cardioversion protocol and assessed its cardioversion efficacy in postoperative patients with recent new onset AF.

\section{Methods}

\section{Patients}

Between December 2011 and September 2012, 24 patients with new onset AF who underwent isolated or combined aortic valve replacement and/or coronary artery bypass surgery performed at our institution were evaluated in this observational prospective study. Inclusion criteria were: age between 18 and 80, duration of new onset AF less than
4 days, body weight less than $100 \mathrm{~kg}$ and no previous treatment with class I or III antiarrhythmic drugs. Preoperative exclusion criteria were: poor left ventricular ejection fraction (LVEF $<40 \%)$, NYHA class III-IV, history of myocardial infarction within 30 days before surgery, long QT syndrome (uncorrected QT interval $>440 \mathrm{~ms}$ ), sick sinus node syndrome, higher degree atrio-ventricular block $\left(\mathrm{II}^{\circ}, \mathrm{III}^{\circ}\right)$ as well as bradyarrhythmia absoluta. Re-do cardiac surgery patients were also excluded from this observation.

Ethical clearance for this observational prospective study was given by the institutional ethics committee of Cologne University. Therefore, according to the Ethics Committee a signed informed consent was not mandatory as both antiarrhythmic drugs used were approved in the ESC Guidelines and the risks are similar to the current standard therapy [15].

\section{Study protocol}

Patients with new onset AF after a cardiac surgical procedure underwent treatment according to the protocol shown in Figure 1. In all patients who were not effectively anticoagulated for more than 48 hours after new onset AF, an elective pre-interventional trans-esophageal echocardiography was performed in order to exclude intracardiac thrombus formations before pharmacological and/or electrical cardioversion were commenced. Before the first vernakalant administration, electrolyte levels (magnesium, potassium) were checked and optimized, if indicated.

Electric cardioversion under sedation with weight adjusted etomidate was only performed in case of persistent AF after sequential pharmacological treatment with both vernakalant and flecainide. A successful cardioversion was defined as a conversion into a stable sinus rhythm within the time periods described in Figure 1.

Furthermore, according to the study protocol, all patients were divided in two groups: patients who successfully converted into a stable SR (converted group) and patients who were not converted into a SR (non-converted group) after single treatment with vernakalant or combination vernakalant/flecainide before EC. Both groups were compared regarding patients baseline preoperative, intraoperative and postoperative characteristics, past medical history, laboratory and echocardiographic parameters before treatment with the view to elaborating possible predictors of nonresponders to pharmacological treatment.

\section{Statistical analysis}

All data were analyzed using Statistical Package for Social Sciences, version 21.0 (SPSS Inc., Chicago, Illinois) and are expressed as the mean \pm standard deviation (SD) in cases of normal distributed or median (interquartile range) in cases of non-normal distributed continuous variables. Variables were tested for normal distribution using 


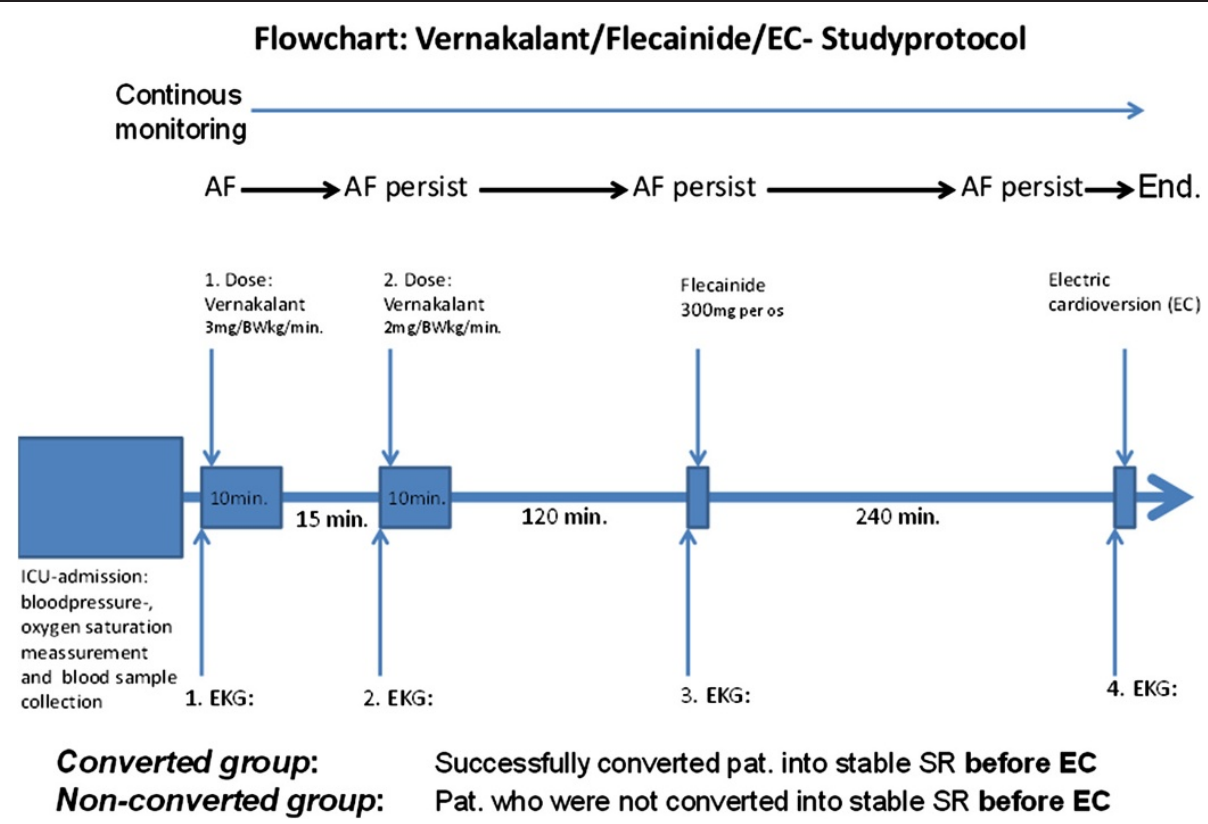

Figure 1 Flowchart of studyprotcol which begins with the admission to ICU with bloodpressure-, oxygen saturation measurement and blood sample collection and ends with EC.

the one sample Kolmogorov-Smirnov test. The Student $t$ test and the Mann-Whitney $U$ test were applied for comparison of continuous variables in case of normal or nonnormal distribution, respectively. Chi-square and Fisher exact test were used for comparison of dichotomous variables. A p-value $<0.05$ was considered to indicate statistical significance.

\section{Results}

Tables 1, 2 and 3 represent basic demographic data, patient comorbidities, medical history, echocardiographic parameters and general clinical characteristics of all patients included in this study.

The mean age of the population was $69.6 \pm 6.3$ years and $26.1 \%$ of patients were female. 14 patients (60.9\%) were successfully converted into a stable sinus rhythm after treatment with vernakalant or combination vernakalant/ flecainide. A stable sinus rhythm could be restored in 12 patients $(52.2 \%)$ after isolated treatment with vernakalant, and in 2 further patients (cumulative 60.9\%) after additional dose of flecainide. One patient refused to proceed with pharmacological treatment after the first dose of vernakalant. Another patient refused EC after not successful drug combination treatment (Figure 2). In total, we were able to achieve a stable SR in 21 patients (95.5\%) after treatment with both antiarrhythmic drugs and EC.

Comparing converters vs. non-converters after pharmacological treatment, there were no statistically significant differences in terms of height, weight, gender distribution, comorbidities, preoperative medication, left ventricular function and left atrium diameter between both groups
(Tables 1, 2 and 3). However, we found that the interventricular septum (IVS) in the non-converted group was significantly thicker compared to the converted group: $14.0 \pm 1.00$ vs. $10.40 \pm 2.59 \mathrm{~mm}(\mathrm{p}=0.036)$.

\section{Discussion}

In this study, we investigated for the first time, a graduated scheme therapy of postcardiotomy AF with vernakalant, flecainide and EC. Notably, previous research on AF after cardiac surgery was limited to the use of single therapy with either vernakalant, other antiarrhythmic drugs or/and EC. By comparing converted vs. nonconverted patients before EC we found significant difference in the thickness of IVS, which therefore might be a potential negative predictor of successful pharmacological cardioversion.

The negative effect of long term AF has been extensively studied in the previous research $[2,16,17]$. The incidence of AF in postcardiotomy patients may also depend on the type of surgery. It occurs in $32-44 \%$ after coronary artery bypass grafting (CABG), 35\% after OPCAB, $42 \%$ after mitral valve, $49 \%-74 \%$ after aortic valve surgery, and $62 \%$ of CABG combined with valve surgery $[2,18]$. AF after cardiac surgery is associated with longer ICU stay and complications, such as low output syndrome, renal failure and stroke [19-22]. There is also a substantial amount of research, mentioned in the updated Guidelines, associating AF with an increased risk of heart failure and high mortality [23]. These facts enhance the importance of rapid cardioversion in order to avoid further adverse events. 
Table 1 Laboratory parameters

\begin{tabular}{|c|c|c|c|c|}
\hline Preoperative laboratory parameters & All & Converted $n=14$ & Non-converted $n=9$ & p-value \\
\hline $\mathrm{aPTT}(\mathrm{sec})$ & $26(24 ; 28)$ & $26.5(24.8 ; 28)$ & $24(24 ; 34)$ & 0.557 \\
\hline Creatinin (mg/dl) & $0.91(0.79 ; 1.14)$ & $0.905(0.81 ; 1.11)$ & $1.0(0.81 ; 1.24)$ & 0.557 \\
\hline CRP (mg/l) & $3.2(3 ; 15.4)$ & $3.2(3 ; 20.8)$ & $3(3 ; 11.8) 0.877$ & 0.877 \\
\hline CK $(U / l)$ & $75.5(63.5 ; 149.8)$ & $77(64.5 ; 138)$ & $76(61 ; 192.5)$ & 0.781 \\
\hline CK-MB (U/l) & $15(15 ; 21)$ & $15(11.5 ; 17)$ & $18(12 ; 25)$ & 0.516 \\
\hline GOT (U/l) & $26(23 ; 28.8)$ & $25.5(19.8 ; 28.5)$ & $27(23 ; 31)$ & 0.557 \\
\hline GPT(U/I) & $21(15 ; 24)$ & $20(14.5 ; 28)$ & $21(16 ; 23.5)$ & 0.744 \\
\hline Hemoglobin (g/dl) & $13.3 \pm 2.1$ & $13.3 \pm 2.4$ & $13.5 \pm 1.9$ & 0.831 \\
\hline Quick (\%) & $90.1 \pm 20.5$ & $89.6 \pm 17.1$ & $89.7 \pm 26.8$ & 0.992 \\
\hline Platelets (x1E9/I) & $211.5 \pm 70.6$ & $207.9 \pm 76.2$ & $216.8 \pm 69.5$ & 0.780 \\
\hline Troponin-T (ug/l) & $0.42 \pm 0.82$ & $0.26 \pm 0.39$ & $0.77 \pm 1.33$ & 0.492 \\
\hline Uric acid (mg/dl) & $46.8 \pm 17.1$ & $49.6 \pm 19.7$ & $44 \pm 12.6$ & 0.460 \\
\hline WCC (x1E9/l) & $8.5 \pm 1.8$ & $8.9 \pm 1.6$ & $8.2 \pm 2$ & 0.370 \\
\hline \multicolumn{5}{|l|}{ Postoperative but before cardioversion } \\
\hline $\mathrm{Ca}(\mathrm{mmol} / \mathrm{l})$ & $2.1 \pm 0.15$ & $2.11 \pm 0.16$ & $2.1 \pm 0.15$ & 0.729 \\
\hline Creatinin (mg/dl) & $1.57 \pm 0.97$ & $1.35 \pm 0.77$ & $2.0 \pm 1.15$ & 0.113 \\
\hline CRP $(\mathrm{mg} / \mathrm{l})$ & $126 \pm 91.5$ & $128.9 \pm 99.5$ & $122.7 \pm 89.2$ & 0.880 \\
\hline Erythrocytes (x1E12/I) & $3.46 \pm 0.34$ & $3.5 \pm 3.9$ & $3.4 \pm 0.2$ & 0.291 \\
\hline Hematocrit (\%) & $31.21 \pm 3.22$ & $31.6 \pm 3.5$ & $31.1 \pm 2.8$ & 0.742 \\
\hline Hemoglobin (g/dl) & $10.15 \pm 1.0$ & $10.3 \pm 1.1$ & $10.1 \pm 0.88$ & 0.741 \\
\hline HbA1c (\%) & $5.83 \pm 0.87$ & $5.8 \pm 0.95$ & $5.9 \pm 0.77$ & 0.924 \\
\hline $\mathrm{MCH}(\mathrm{pg})$ & $29.4 \pm 1.53$ & $29.0 \pm 1.4$ & $29.9 \pm 1.7$ & 0.178 \\
\hline MCV (fl) & $90.0 \pm 4.04$ & $88.9 \pm 3.3$ & $91.6 \pm 4.9$ & 0.127 \\
\hline $\mathrm{Mg}(\mathrm{mmol} / \mathrm{l})$ & $1.05 \pm 0.28$ & $1.11 \pm 0.34$ & $0.96 \pm 0.19$ & 0.267 \\
\hline NtproBNP (ng/l) & $1576(833 ; 3573)$ & $1463(721 ; 2772)$ & $3102(1087 ; 11838)$ & 0.185 \\
\hline Potassium (mmol/l) & $4.70 \pm 0.64$ & $4.5 \pm 0.49$ & $4.9 \pm 0.83$ & 0.153 \\
\hline PTC (ug/l) & $0.5(0.2 ; 0.88)$ & $0.6(0.2 ; 0.75)$ & $0.4(0.23 \pm 3.5)$ & 0.645 \\
\hline Platelets (x1E9/I) & $219.3 \pm 82.2$ & $214.1 \pm 93.5$ & $232.6 \pm 68.7$ & 0.616 \\
\hline Sodium (mmol/l) & $140.4 \pm 3.7$ & $140.1 \pm 3.4$ & $141.2 \pm 4.3$ & 0.511 \\
\hline TSH (mU/l) & $2.37 \pm 3.97$ & $2.9 \pm 4.9$ & $1.7 \pm 1.9$ & 0.501 \\
\hline WCC (x1E9/l) & $12.25 \pm 5.5$ & $12.12 \pm 4.9$ & $12.9 \pm 6.7$ & 0.761 \\
\hline
\end{tabular}

aPTT: activated partial thromboplastin time, CK: creatine kinase, CRP: c-reactive protein, GOT:glutamic oxaloacetic transaminase, GPT: glutamate pyruvate transaminase, $\mathrm{HbA1c}$ : Glycated haemoglobin, MCH: mean corpuscular haemoglobin, MCV: mean corpuscular volume, NtproBNP: N-terminal prohormone of brain natriuretic peptide, PTC: procalcitonin, TSH:thyroid-stimulating hormone, WCC: white cell counts.

Flecainide is a class Ic antiarrhythmic agent which plays an important role in rhythm control in patients with AF and can be administered both orally and intravenously. Vernakalant is a new alternative intravenous atrial selective antiarrhythmic drug developed for rapid conversion of AF into sinus rhythm [24]. This is a sodium- and potassiumchannel blocking agent, which effects all phases $(0-$ IV) of the atrial action potential (AP) and terminates AF by increasing the atrial effective refractory period (AERP) by blocking the potassium ( $\mathrm{I}_{\mathrm{Kur}}, \mathrm{I}_{\mathrm{KACh}}, \mathrm{I}_{\mathrm{Kr}}$ and $\mathrm{I}_{\mathrm{to}}$ ) and sodium currents $\left(\mathrm{I}_{\mathrm{Na}}\right)$ in a concentration-, rate- and voltage-dependent manner [25].
The effect of vernakalant on the treatment of recentonset atrial fibrillation has been widely debated in the previous research [7,26-29]. Also, the negative influence of IVS on the conversion into a sinus rhythm has been already indirectly mentioned in the literature. Furthermore, recent studies reported that the incidence of postoperative AF was higher in patients with aortic valve replacement [2]. This is generally consistent with our results as patients with hypertrophied myocardium and therefore hypertrophied IVS usually have severe aortic stenosis which was treated with surgical aortic valve replacement in our study. Therefore, taking into consideration results of previous 
Table 2 Baseline characteristics, past medical history and preoperative medication

\begin{tabular}{|c|c|c|c|c|}
\hline & All & Converted $n=14$ & Non-converted $\mathrm{n}=9$ & p-value \\
\hline Age & $69.63 \pm 6.34$ & $68.21 \pm 7.21$ & $71.22 \pm 4.58$ & 0.279 \\
\hline CVA (\%) & 13 & 21.4 & 0 & 0.253 \\
\hline COPD (\%) & 13 & 14.3 & 11.1 & 1.000 \\
\hline Diabetis mellitus (\%) & 17.4 & 14.3 & 22.2 & 1.000 \\
\hline Female (\%) & 26.1 & 21.4 & 33.3 & 0.643 \\
\hline Height (cm) & $172.71 \pm 8.33$ & $172.64 \pm 8.28$ & $172 \pm 9$ & 0.862 \\
\hline Hyperlipidemia (\%) & 43.5 & 42.9 & 44.4 & 1.000 \\
\hline Hypertension (\%) & 78.3 & 78.6 & 77.8 & 1.000 \\
\hline PAD (\%) & 8.7 & 7.1 & 11.1 & 1.000 \\
\hline Renal insufficiency or creatinin >1.1 (\%) & 8.7 & 7.1 & 11.1 & 1.000 \\
\hline Smoker (\%) & 21.7 & 28.6 & 11.1 & 0.611 \\
\hline Weight (kg) & $80.56 \pm 13.17$ & $81.24 \pm 14.26$ & $79.33 \pm 12.87$ & 0.748 \\
\hline ACE-inhibitors(\%) & 36.4 & 23.1 & 55.6 & 0.187 \\
\hline Aspirin (\%) & 86.4 & 84.6 & 88.9 & 1.000 \\
\hline Beta-blockers (\%) & 72.7 & 69.2 & 77.8 & 1.000 \\
\hline Ca-antagonist (\%) & 36.4 & 30.8 & 44.4 & 0.662 \\
\hline Clopidogrel (\%) & 4.5 & 7.7 & 0 & 1.000 \\
\hline Cortison (\%) & 4.5 & 7.7 & 0 & 1.000 \\
\hline Diuretics (\%) & 31.8 & 38.5 & 22.2 & 0.648 \\
\hline Statin (\%) & 63.6 & 69.2 & 55.6 & 1.000 \\
\hline
\end{tabular}

COPD: chronic obstructive pulmonary disease,CVA: cerebrovascular accident, PAD: peripheral arterial disease.

Table 3 Intraoperative, postoperative and echocardiography data

\begin{tabular}{|c|c|c|c|c|}
\hline & All & Converted $n=14$ & Non-converted $n=9$ & $\mathrm{p}$-value \\
\hline Cardioplegia type & & & & 0.444 \\
\hline Buckberg (\%) & 40 & 46.3 & 28.6 & \\
\hline Calafiore (\%) & 60 & 53.8 & 71.4 & \\
\hline CPB time (min) & $109.86 \pm 51.3$ & $122.15 \pm 59.54$ & $94.13 \pm 33.01$ & 0.240 \\
\hline Operation duration (min) & $233.52 \pm 88.41$ & $242.92 \pm 114.4$ & $223.33 \pm 38.58$ & 0.628 \\
\hline Operation urgency & & & & 0.441 \\
\hline Emergent (\%) & 4.3 & 7.1 & 0.0 & \\
\hline Urgent (\%) & 13 & 7.1 & 22.2 & \\
\hline Elective (\%) & 82.6 & 85.7 & 77.8 & \\
\hline Reperfusion time (min) & $36.41 \pm 22.08$ & $38 \pm 26.32$ & $36.63 \pm 14.11$ & 0.894 \\
\hline Total ischemic time (min) & $64.05 \pm 33.66$ & $71.46 \pm 38.27$ & $52.5 \pm 25.13$ & 0.230 \\
\hline Hospital stay (days) & $16.29 \pm 5.72$ & $16.4 \pm 6.29$ & $15.67 \pm 5.61$ & 0.818 \\
\hline Intensive care unit stay (days) & $4(2.75 ; 6.25)$ & $4(3 ; 6)$ & $4(2 ; 19.5)$ & 0.972 \\
\hline IABP & 5 & 0 & 14.3 & 0.350 \\
\hline Ventilation duration (in hours) & $17.45 \pm 8.44$ & $18.94 \pm 10.31$ & $49.67 \pm 13.32$ & 0.256 \\
\hline Ejection fraction (\%) & $55.82 \pm 9.68$ & $58 \pm 8.43$ & $42.33 \pm 5.51$ & 0.779 \\
\hline Left atrium (mm) & $43.22 \pm 7.5$ & $41 \pm 6.56$ & $42.33 \pm 5.51$ & 0.779 \\
\hline Mitral insufficiency (\%) & 20 & 25 & 0 & 1.000 \\
\hline Interventricular septum (mm) & $11.5 \pm 2.59$ & $10.43 \pm 2.3$ & $14 \pm 1$ & 0.036 \\
\hline
\end{tabular}

CPB: Cardiopulmonary bypass, IABP: Intra-aortic balloon pump. 


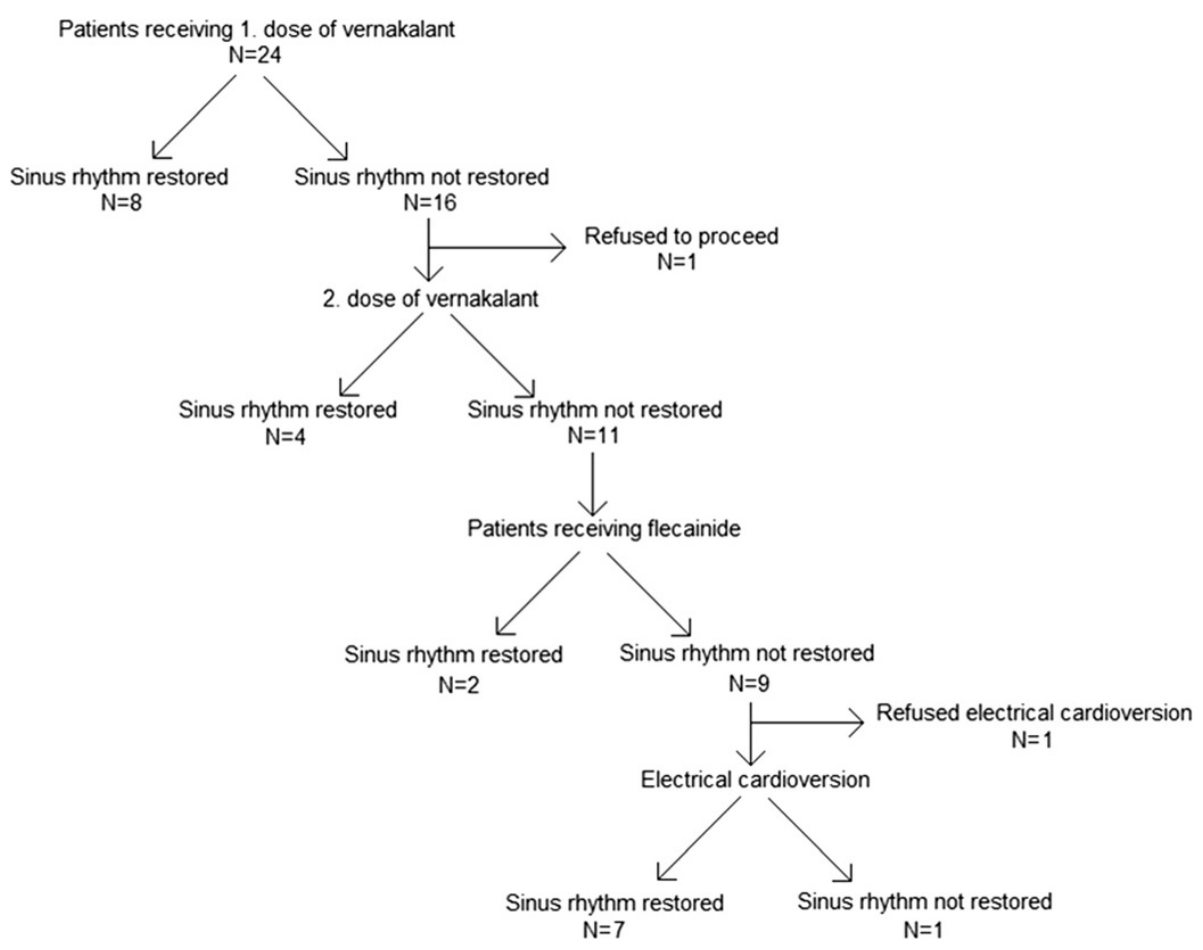

Figure 2 Flowchart of studydesign and success of antiarrhythmic drugs and EC.

research and our study and despite the small patient cohort in the present observation, thickness of the IVS might play a significant role in affecting the success of pharmacological conversion rate.

Analyzing data on pharmacological conversion rate in postcardiotomy patients and patients who had not undergone cardiac surgery, we found out that application of both vernakalant and flecainide as monotherapy was associated with worse conversion rates in postcardiotomy patients. Kowey et al. in his prospective randomized double-blind trial reported on the success rate of conversion with vernakalant into a sinus rhythm in postcardiotomy patients which was $47 \%$ compared to the success rate in nonsurgical patients of up to $55 \%[7,26]$. While there were no useful data regarding conversion rate of postcardiotomy patients after flecainide treatment, the success rate to this drug in non-cardiac surgery patients ranged between 50 $67.5 \%$ in the previous literature [30-33]. Not surprisingly, our findings showed a conversion rate after vernakalant monotherapy which was slightly higher however comparable to the study by Kowey et al. and resulted in $52.2 \%$ of success. Furthermore, our study showed a significant improvement in the conversion rate into a stable sinus rhythm to $60.9 \%$ after additional application of flecainide in patients who did not convert after monotherapy with vernakalant. In interpreting these findings, we assume that the combination of both antiarrhythmic drugs is more effective in converting recent onset atrial fibrillation in carefully selected groups of patients with AF after cardiac surgery. This might be also important in regards to the fact that a substantial number of patients resist EC due to sedation and further fears related to this more demanding procedure. Despite that, our analysis revealed a $91.3 \%$ conversion rate into a stable sinus rhythm after treatment with both antiarrhythmics and EC. Taking into consideration the fact that two patients who were not converted in a sinus rhythm after vernakalant and flecainide administration, refused further electric cardioversion attempt, the combined cardioversion rate might have been even higher.

Several authors suggested that the use of flecainide in patients with structural heart defects may contribute to a pro-arrhythmogenic side effects [34,35]. These studies are particularly focused on the risk of ventricular arrhythmia in patients with previous coronary heart disease and myocardial infarction or ischemic cardiomyopathy. Therefore, we excluded patients with ischemic cardiomyopathy and previous myocardial infarction from our observation, as mentioned before. Furthermore, vernakalant with the most common side-effects being dysgeusia, sneezing, paresthesia, nausea, and hypotension appeared to have no side-effects even in combination with flecainide in our study. Also, there were no drug-induced life-threatening ventricular arrhythmias observed after combinational treatment with vernakalant/flecainide. However, it might be related to the relatively low number of patients observed in our investigation. 
"Classic" antiarrhythmic drugs, such as amiodaron or Beta-blockers were also shown to be an effective treatment in post cardiotomy patients [36]. Compared to a high conversion rate and quick action of vernakalant shown in our study and previous research, amiodaron treatment for recent-onset AF only resulted in 5\% conversion within the first 90 min with similar results in post cardiotomy patients [37]. However, well-designed trials evaluating amiodarone and focused on postoperative medical cardioversion are lacking. Also, treatment with this drug can lead to serious complications such as non-cardiac toxicity including pulmonary, hepatic, thyroid, and neurologic side-effects. Moreover, its intravenous administration can be associated with hypotension, bradycardia, and thrombophlebitis, and this agent should be used with caution in patients with severe pulmonary disease and low pulmonary resistance. In contrast, vernakalant is the first marketed drug with relative atrial selectivity and low rate of adverse events reported, indicating a higher safety profile. Beta-blockers are also relatively safe in terms of adverse events, however they are mainly used as the main agents for ventricular rate control rather than for rhythm control [36].

The result of our study may be interpreted to indicate that the oral application of $300 \mathrm{mg}$ flecainide added to intravenously administered vernakalant in patients who did not convert into a sinus rhythm may not only increase the cardioversion rate but also prevent pro-arrhytmogenity and reduce side effects of vernakalant. Recent studies showed that the oral application of a single flecainide dose of $300 \mathrm{mg}$ in patients with structural heart disease is safe and effective in carefully selected patients [2,38].

Our study has several limitations. The main limitation is its non-randomized design and analysis of limited number of patients from a single institution. Furthermore, previous usual therapy strategies with non-class III antiarrhythmics, such as Beta-blockers, as well as electrolytes were not quantified. Larger prospective randomized studies with this aggressive therapy protocol are needed to confirm our preliminary results.

\section{Conclusion}

Our results show that the sequential combinational treatment with vernakalant, flecainide and EC is a recommendable and effective therapy strategy to convert rapidly new onset AF in carefully selected patients after cardiac surgery.

\section{Abbreviations \\ AERP: Atrial effective refractory period; AF: Atrial fibrillation; AP: Action potential; CABG: Coronary artery bypass grafting; EC: Electric cardioversion; IVS: Interventricular septum; SR: Sinus rhythm.}

\section{Competing interests}

The authors report no competing interests.

\section{Author's contributions}

MZ, AS and JF participated in the study design, recruited patients, analysed the data and drafted the manuscript. HR, AFP, LK and PBR participated in the study design, data analysis and study coordination. TW, LK, YHC, JW and TW participated in the design of the study and supervised the trial process. All authors read and approved the final manuscript.

\section{Author's information}

Mohamed Zeriouh, Anton Sabashnikov and Yeong-Hoon Choi share the first/ senior author designation.

\section{Acknowledgement}

There are no sources of funding. The authors have no affiliations or financial involvement with any organization or entity with a financial interest in or financial conflict with the subject matter or materials discussed in the manuscript. This includes employment, consultancies, honoraria, stock ownership or options, expert testimony, grants or patents received or pending, or royalties.

\section{Author details}

${ }^{1}$ Department of Cardiothoracic Surgery, Heart Center of the University of Cologne, Cologne, Germany. ${ }^{2}$ Department of Cardiology, Pneumology and Angiology, Heart Center of the University of Cologne, Cologne, Germany. ${ }^{3}$ Center for Molecular Medicine Cologne, University of Cologne, Cologne, Germany. ${ }^{4}$ Department of Thoracic and Cardiovascular Surgery, University Hospital of Goettingen, Goettingen, Germany.

Received: 16 January 2014 Accepted: 24 April 2014

Published: 12 May 2014

\section{References}

1. Camm AJ, Kirchhof P, Lip GY, Schotten U, Savelieva I, Ernst S, Van Gelder IC, Al-Attar N, Hindricks G, Prendergast B, Heidbuchel H, Alfieri O, Angelini A, Atar D, Colonna P, De Caterina R, De Sutter J, Goette A, Gorenek B, Heldal M, Hohloser SH, Kolh P, Le Heuzey JY, Ponikowski P, Rutten FH: Guidelines for the management of atrial fibrillation: the Task Force for the Management of Atrial Fibrillation of the European Society of Cardiology (ESC). Eur Heart J 2010, 31:2369-2429.

2. Helgadottir S, Sigurdsson MI, Ingvarsdottir IL, Arnar DO, Gudbjartsson T: Atrial fibrillation following cardiac surgery: risk analysis and long-term survival. J Cardiothorac Surg 2012, 7:87.

3. Ommen SR, Odell JA, Stanton MS: Atrial arrhythmias after cardiothoracic surgery. N Engl J Med 1997, 336:1429-1434.

4. Blaauw Y, Crijns HJ: Treatment of atrial fibrillation. Heart 2008, 94:1342-1349.

5. Shenasa M, Soleimanieh M, Shenasa F: Individualized therapy in patients with atrial fibrillation: new look at atrial fibrillation. Europace 2012, 14(Suppl 5):v121-v124

6. Dunning J, Treasure T, Versteegh M, Nashef SA: Guidelines on the prevention and management of de novo atrial fibrillation after cardiac and thoracic surgery. Eur J Cardiothorac Surg 2006, 30:852-872.

7. Bash LD, Buono JL, Davies GM, Martin A, Fahrbach K, Phatak H, Avetisyan R, Mwamburi M: Systematic review and meta-analysis of the efficacy of cardioversion by vernakalant and comparators in patients with atrial fibrillation. Cardiovasc Drugs Ther 2012, 26:167-179.

8. Wijffels MC, Kirchhof CJ, Dorland R, Allessie MA: Atrial fibrillation begets atrial fibrillation. A study in awake chronically instrumented goats. Circulation 1995, 92:1954-1968.

9. Cosio FG, Aliot E, Botto GL, Heidbuchel H, Geller CJ, Kirchhof P, De Haro JC, Frank R, Villacastin JP, Vijgen J, Crijns H: Delayed rhythm control of atrial fibrillation may be a cause of failure to prevent recurrences: reasons for change to active antiarrhythmic treatment at the time of the first detected episode. Europace 2008, 10:21-27.

10. Lip GY, Tse HF: Management of atrial fibrillation. Lancet 2007, 370:604-618.

11. Schilling RJ: Cardioversion of atrial fibrillation: the use of antiarrhythmic drugs. Heart 2010, 96:333-338.

12. Vizzardi E, Salghetti F, Bonadei I, Gelsomino S, Lorusso R, D'Aloia A, Curnis A: A new antiarrythmic drug in the treatment of recent onset atrial fibrillation: vernakalant. Cardiovasc Ther 2013, 31(5):e55-e62.

13. Apostolakis S, Oeff M, Tebbe U, Fabritz L, Breithardt G, Kirchhof P: Flecainide acetate for the treatment of atrial and ventricular arrhythmias. Expert Opin Pharmacother 2013, 14:347-357.

14. Rajagopalan B, Curtis AB: Contemporary approach to electrical and pharmacological cardioversion of atrial fibrillation. Postgrad Med 2012, 124:26-35. 
15. Camm AJ, Lip GY, De Caterina R, Savelieva I, Atar D, Hohnloser SH, Hindricks G, Kirchhof P, Bax JJ, Baumgartner H, Ceconi C, Dean V, Deaton C, Fagard R, Funck-Brentano C, Hasdai D, Hoes A, Kirchhof P, Knuuti J, Kolh P, McDonagh T, Moulin C, Popescu BA, Reiner Z, Sechtem U, Sirnes PA, Tendera M, Torbicki A, Vahanian A, Windecker S, et al: Focused update of the ESC Guidelines for the management of atrial fibrillation: an update of the 2010 ESC Guidelines for the management of atrial fibrillation. Developed with the special contribution of the European Heart Rhythm Association. Eur Heart J 2012, 33:2719-2747.

16. Horwich P, Buth KJ, Legare JF: New onset postoperative atrial fibrillation is associated with a long-term risk for stroke and death following cardiac surgery. J Card Surg 2013, 28:8-13.

17. Mediratta N, Chalmers J, Pullan M, McShane J, Shaw M, Poullis M: In-hospital mortality and long-term survival after coronary artery bypass surgery in young patients. Eur J Cardiothorac Surg 2013, 43(5):1014-1021.

18. Creswell LL, Schuessler RB, Rosenbloom M, Cox JL: Hazards of postoperative atrial arrhythmias. Ann Thorac Surg 1993, 56:539-549.

19. Eltheni R, Giakoumidakis K, Brokalaki H, Galanis P, Nenekidis I, Fildissis G: Predictors of Prolonged Stay in the Intensive Care Unit following Cardiac Surgery. ISRN Nurs 2012, 2012:691561.

20. Borzak S, Tisdale JE, Amin NB, Goldberg AD, Frank D, Padhi ID, Higgins RS: Atrial fibrillation after bypass surgery: does the arrhythmia or the characteristics of the patients prolong hospital stay? Chest 1998, 113:1489-1491.

21. Andersson T, Magnuson A, Bryngelsson IL, Frobert O, Henriksson KM Edvardsson N, Poci D: All-cause mortality in 272186 patients hospitalized with incident atrial fibrillation 1995-2008: a Swedish nationwide long-term case-control study. Eur Heart J 2013, 34(14):1061-1067.

22. Saxena A, Dinh DT, Smith JA, Shardey GC, Reid CM, Newcomb AE: Usefulness of postoperative atrial fibrillation as an independent predictor for worse early and late outcomes after isolated coronary artery bypass grafting (multicenter Australian study of 19,497 patients). Am J Cardiol 2012, 109:219-225.

23. Fuster V, Ryden LE, Cannom DS, Crijns HJ, Curtis AB, Ellenbogen KA, Halperin JL, Kay GN, Le Huezey JY, Lowe JE, Olsson SB, Prystowsky EN, Tamargo JL, Wann LS: 2011 ACCF/AHA/HRS focused updates incorporated into the ACC/AHA/ESC 2006 Guidelines for the management of patients with atrial fibrillation: a report of the American College of Cardiology Foundation/American Heart Association Task Force on Practice Guidelines developed in partnership with the European Society of Cardiology and in collaboration with the European Heart Rhythm Association and the Heart Rhythm Society. J Am Coll Cardiol 2011, 57:e101-e198.

24. Ehrlich JR, Nattel S: Novel approaches for pharmacological management of atrial fibrillation. Drugs 2009, 69:757-774.

25. Blomstrom-Lundqvist C, Blomstrom P: Safety and efficacy of pharmacological cardioversion of atrial fibrillation using intravenous vernakalant, a new antiarrhythmic drug with atrial selectivity. Expert Opin Drug Saf 2012, 11:671-679.

26. Kowey PR, Dorian P, Mitchell LB, Pratt CM, Roy D, Schwartz PJ, Sadowski J, Sobczyk D, Bochenek A, Toft E: Vernakalant hydrochloride for the rapid conversion of atrial fibrillation after cardiac surgery: a randomized, double-blind, placebo-controlled trial. Circ Arrhythm Electrophysiol 2009, 2:652-659.

27. Roy D, Rowe BH, Stiell IG, Coutu B, Ip JH, Phaneuf D, Lee J, Vidaillet $H$, Dickinson G, Grant S, Ezrin AM, Beatch GN: A randomized, controlled trial of RSD1235, a novel anti-arrhythmic agent, in the treatment of recent onset atrial fibrillation. J Am Coll Cardiol 2004, 44:2355-2361.

28. Roy D, Pratt CM, Torp-Pedersen C, Wyse DG, Toft E, Juul-Moller S, Nielsen T, Rasmussen SL, Stiell IG, Coutu B, Ip JH, Pritchett EL, Camm AJ: Vernakalant hydrochloride for rapid conversion of atrial fibrillation: a phase 3 , randomized, placebo-controlled trial. Circ 2008, 117:1518-1525.

29. Pratt CM, Roy D, Torp-Pedersen C, Wyse DG, Toft E, Juul-Moller S, Retyk E, Drenning DH: Usefulness of vernakalant hydrochloride injection for rapid conversion of atrial fibrillation. Am J Cardiol 2010, 106:1277-1283.

30. Kondili A, Kastrati A, Popa Y: Comparative evaluation of verapamil, flecainide and propafenone for the acute conversion of atrial fibrillation to sinus rhythm. Wien Klin Wochenschr 1990, 102:510-513.

31. Donovan KD, Power BM, Hockings BE, Dobb GJ, Lee KY: Intravenous flecainide versus amiodarone for recent-onset atrial fibrillation. Am J Cardiol 1995, 75:693-697.
32. Reisinger J, Gatterer E, Lang W, Vanicek T, Eisserer G, Bachleitner T, Niemeth C, Aicher F, Grander W, Heinze G, Kuhn P, Siostrzonek P: Flecainide versus ibutilide for immediate cardioversion of atrial fibrillation of recent onset. Eur Heart J 2004, 25:1318-1324.

33. Alp NJ, Bell JA, Shahi M: Randomised double blind trial of oral versus intravenous flecainide for the cardioversion of acute atrial fibrillation. Heart 2000, 84:37-40.

34. Preliminary report: effect of encainide and flecainide on mortality in a randomized trial of arrhythmia suppression after myocardial infarction, The Cardiac Arrhythmia Suppression Trial (CAST) Investigators. N Engl J Med, 321(1989):406-412.

35. Anderson JL, Platia EV, Hallstrom A, Henthorn RW, Buckingham TA, Carlson MD, Carson PE: Interaction of baseline characteristics with the hazard of encainide, flecainide, and moricizine therapy in patients with myocardial infarction. A possible explanation for increased mortality in the Cardiac Arrhythmia Suppression Trial (CAST). Circ 1994, 90:2843-2852.

36. Khanderia U, Wagner D, Walker PC, Woodcock B, Prager R: Amiodarone for atrial fibrillation following cardiac surgery: development of clinical practice guidelines at a university hospital. Clin Cardiol 2008, 31:6-10.

37. Philip I, Berroeta C, Leblanc I: Perioperative challenges of atrial fibrillation. Curr Opin Anaesthesio/ 2014, [Epub ahead of print]

38. Er F, Aslan O, Caglayan E, Gassanov N, Nia AM, Erdmann E, Rosenkranz S: Flecainide for cardioversion in patients at elevated cardiovascular risk and persistent atrial fibrillation: a prospective observational study. Clin Res Cardiol 2010, 99:369-373.

doi:10.1186/1749-8090-9-83

Cite this article as: Zeriouh et al.: A novel treatment strategy of new onset atrial fibrillation after cardiac surgery: an observational prospective study. Journal of Cardiothoracic Surgery 2014 9:83.

\section{Submit your next manuscript to BioMed Central and take full advantage of:}

- Convenient online submission

- Thorough peer review

- No space constraints or color figure charges

- Immediate publication on acceptance

- Inclusion in PubMed, CAS, Scopus and Google Scholar

- Research which is freely available for redistribution 